\title{
Avaliação externa como parâmetro para a Educação
}

\author{
Margarida Maria de Souza Santos Albuquerque ${ }^{1}$
}

\begin{abstract}
Resumo: Analisa-se, neste artigo, a avaliação da educação em larga escala, a Avaliação Nacional do Rendimento Escolar (Anresc/Prova Brasil), a partir dos resultados obtidos desde sua primeira edição em 1991. Articulando o resultado das avaliações à politicas de responsabilização, com atribuições de consequências para os gestores e educadores escolares. Tendo como base de análise os objetivos e metas dessas avaliações, bem como pesquisas bibliográficas que geraram fatos relevantes sobre o tema. Discutem-se os riscos que as avaliações padronizadas como a Prova Brasil, que referenciam políticas de responsabilização, exacerbam a preocupação dos gestores e professores com as atividades desenvolvidas para a preparação dos educandos para esse teste, o que pode acarretar uma redução dos conteúdos escolares, alterando o currículo escolar. Por outro lado, o resultado dessas avaliações podem levar os gestores e educadores a refletir, através da informações levantadas, sobre o currículo escolar e quais as habilidades de leitura e matemática devem ser melhor trabalhadas para garanti-las a todos os educandos, ou seja, tornar a aprendizagem mais significativa e eficaz.
\end{abstract}

Palavras-chave: Avaliação - Educação - Prova Brasil- Responsabilização - Currículo.

\section{Avaliação externa como parâmetro para a Educação}

\begin{abstract}
It is analyzed in this article, the evaluation of large-scale education, the National School Performance Assessment (Anresc / Proof Brazil), from the results obtained since its first edition in 1991. Articulating the results of the evaluations of the policies accountability, with assignments consequences for managers and school teachers. Based on analysis of the objectives and goals of these assessments, as well as bibliographic research that generated relevant facts on the subject. the risks that standardized tests are discussed as Proof Brazil, that reference accountability policies exacerbate the concern of managers and teachers with the activities for the preparation of students for this test, which may result in a reduction of educational content, changing the school curriculum. On the other hand, the outcome of these assessments can lead managers and educators to think through the information acquired on the school curriculum and what reading and math skills should be better worked to guarantee them to all students, ie, make more meaningful and effective learning.
\end{abstract}

Keywords: Evaluation - Education - Proof Brazil- Accountability - Curriculum.

\section{Introdução}

Nas duas últimas décadas as avaliações estão presentes nas formulações e implementações das políticas educacionais brasileiras. Essas iniciativas viabilizam a promoção da qualidade do ensino, estabelecendo, dentro das possibilidades, novos parâmetros de gestão dos sistemas educacionais.

\footnotetext{
${ }^{1}$ Mestranda em Educação pela Anne Sullivan University . Especialista em Gestão Escolar pela Faculdade de Juazeiro do Norte - CE - FJN e Especialista em Matemática do Ensino Médio pela Universidade Regional do Cariri - URCA. Graduação em Matemática pela Universidade Regional do Cariri - URCA. Coordenadora Escolar na E.E.F.M. Presidente Geisel (Polivalente-Juazeiro do Norte), Secretária da Educação Básica do Estado do Ceará (SEDUC), Professora assistente - nível A da Faculdade de Juazeiro do Norte - CE (FJN).
} 
Percebe-se uma tendência de centralização da forma de regularização dos currículos escolares, observando-se que as avaliações centralizadas estão sendo utilizadas, para mensurar o rendimento escolar dos educandos, sob os mesmos parâmetros curriculares, o que equipara o conhecimento que todos os educandos deveriam ter acesso.

Dessa forma, percebe-se que nas avaliações externas há uma universalização dos conteúdos, considerando-se pouquíssima variabilidade nos currículos escolares, acontecendo dentro do país e fora dele também, como é o caso do Programa Internacional de Avaliação de Estudantes (PISA), que equipara os países, aparentando um consenso mundial em relação aos currículos, a partir da ideia que o currículo de cada país é comparável aos demais países envolvidos.

Atualmente, participam do Pisa os 34 países membros da OCDE e vários países convidados. Os resultados do Pisa 2012 congregaram 65 países, entretanto este total congrega algumas economias que não podem ser consideradas países, como Hong Kong, Macao, Shangai e Taiwan (INEP, 2016).

$\mathrm{Na}$ tentativa de gerar médias estatísticas mais confiáveis, a amostra brasileira no pisa vem aumentando gradativamente de uma edição para outra, tendo representatividade dos 27 países da federação; Adotando-se como parâmetro a organização administrativa da escola (pública ou privada), a localização (rural ou urbana) e o Índice de Desenvolvimento Humano (IDH) do Estado.

Em fim, o objetivo das avaliações externas (PISA/SPAECE/PROVA BRASIL/ENEM) é produzir indicadores que contribuam para a reflexão da qualidade da educação no país, de modo a subsidiar políticas de melhoria do ensino básico. As avaliações procuram verificar até que ponto as escolas estão preparando os educandos para exercer o seu papel de cidadãos na sociedade onde estão inseridos.

Além de observar as competências dos estudantes nas áreas dos conhecimentos (Linguagem e Códigos, Ciências da Natureza e Ciências Humanas), levantando informações para a elaboração de indicadores contextuais, os quais possibilitam relacionar o desempenho dos educandos a variáveis demográficas, socioeconômicas e educacionais. Essas informações são adquiridas por meio da aplicação de questionários específicos para os alunos, professores e gestores. 
Id on Line Revista Multidisciplinar e de Psicoloqia

Id on Line Multidisciplinary and Psycology Journal

Assim, os resultados desses estudos podem ser utilizados pelos governantes como instrumento de trabalho na definição e reformulação de políticas educacionais, tornando mais efetiva a formação dos educandos para a sua atuação na sociedade, tornando-os proativos no processo.

Enquanto, os gestores escolares, em parceria com os educadores, podem utilizar os resultados dessas avaliações para redirecionar as ações pedagógicas, fazendo as devidas intervenções, tendo como base as competências e habilidades que precisam ser trabalhadas, de acordo com as informações obtidas nas avaliações externas, respeitando a faixa etária e a série de cada educando.

Dessa forma, viabilizar um processo de aprendizagem mais eficaz, onde os educandos apreendem e superam os obstáculos que aparecem, com a colaboração de uma equipe comprometida com uma educação de melhor qualidade.

Além dessa perspectiva as avaliações têm características próprias que as diferenciam no Brasil, a saber:

- As avaliações de caráter diagnóstico, sem consequências diretas para a escola. A divulgação do resultado é feita nas redes sociais, para consulta de toda a sociedade, ou em outras mídias sem o resultado ser devolvido para a escola.

- As avaliações que tem a finalidade de subsidiar, com base nos resultados dos educandos, política de responsabilização para os gestores e educadores escolares. Além de divulgar o resultado nas redes sociais, para consulta de toda a sociedade, ou em outras mídias devolve o resultado para as escolas, podendo ter responsabilidade simbólica ou material, pressupõe que o conhecimento dos resultados pela comunidade escolar, favorece a mobilização da equipe escolar para melhoria da educação, bem como a cobrança dos pais sobre a escola (simbólica); Quando contemplam penalidades ou recompensas em decorrência dos resultados dos educandos e das escolas. Incluindo a responsabilização explicitadas em normas e que envolvem formas de remuneração em função das metas estabelecidas. 
Id on Line Revista Multidisciplinar e de Psicologia

Id on Line Multidisciplinary and Psycology Journal

Segundo Brooke, quando as consequências dessas políticas são apenas simbólicas, elas são chamadas de low stakes ou de responsabilização branda. Enquanto que as consequências sérias são chamadas de high stakes ou de responsabilização forte (BROOKE, 2006).

\section{Avaliação em larga escala Saeb}

Desde a década de trinta, o governo mostrava-se interessado em tornar as avaliações como parte do planejamento educacional, o que ocorreu somente no inicio da década de oitenta, onde a avaliação passou a integrar políticas e práticas governamentais direcionadas a educação básica.

[...] foram necessários mais ou menos cinco décadas para que a avaliação (externa, em larga escala, centralizada e com foco no rendimento do aluno e no desempenho dos sistemas de ensino) viesse a ser introduzida como prática sistemática no governo da educação básica brasileira. ((FREITAS, 2007)

Assim, surge a primeira iniciativa de organização de uma sistemática de avaliação dos ensinos fundamental e médio no território nacional. A qual passou a ser denominada pelo Ministério da Educação (MEC), desde 1991, como Sistema Nacional de Avaliação da Educação Básica (Saeb).

Segundo o Instituto Nacional de Estudos e Pesquisas Educacionais Anisio Teixeira (INEP), desde, sua primeira edição, o Saeb tem como objetivo diagnosticar e monitorar a qualidade da educação básica, nas regiões geográficas e nos Estados brasileiros. A partir de 1995, foram incorporadas novas metodologias que se solidificaram e fazem parte da estrutura atual, a saber:

- Inclusão da rede particular de ensino na amostra.

- Adoção da Teoria de Resposta ao Item (TRI), que permite estimular as habilidades dos educandos independente dos conjuntos específicos dos itens respondidos.

- Opção de trabalhar com os anos finais de cada ciclo escolar $\left(6^{\circ}\right.$ e $9^{\circ}$ ano do ensino fundamental e $3^{\circ}$ ano do ensino médio).

- Priorização das áreas de conhecimento de língua portuguesa (foco em leitura) e matemática (foco na resolução de problemas).

- Participação das 27 unidades federativas. 
Id on Line Revista Multidisciplinar e de Psicologia

Id on Line Multidisciplinary and Psycology Journal

- Adoção de questionários para os alunos sobre características socioculturais e hábitos de estudo. Desde então, o Saeb tornou viável a comparação do rendimento dos alunos nas áreas e anos avaliados.

Vale ressaltar que o Saeb é composto por três avaliações em larga escala, que são: Avaliação Nacional da Educação Básica (Aneb), Avaliação Nacional do Rendimento Escolar (Anresc/Prova Brasil) e Avaliação Nacional da Alfabetização (ANA).

Ainda, segundo o Instituto Nacional de Estudos e Pesquisas Educacionais Anisio Teixeira (INEP):

- Avaliação Nacional da Educação Básica - Aneb: abrange, de maneira amostral, alunos das redes públicas e privadas do país, em áreas urbanas e rurais, matriculados no $5^{\circ}$ ano e $9^{\circ}$ ano do Ensino Fundamental e no $3^{\circ}$ ano do Ensino Médio, tendo como principal objetivo avaliar a qualidade, a equidade e a eficiência da educação brasileira. Apresenta os resultados do país como um todo, das regiões geográficas e das unidades da federação.

- Avaliação Nacional do Rendimento Escolar - Anresc (também denominada "Prova Brasil"): trata-se de uma avaliação censitária envolvendo os alunos do $5^{\circ}$ ano e $9^{\circ}$ ano do Ensino Fundamental das escolas públicas das redes municipais, estaduais e federais, com o objetivo de avaliar a qualidade do ensino ministrado nas escolas públicas. Participam desta avaliação as escolas que possuem, no mínimo, 20 alunos matriculados nas séries/anos avaliados, sendo os resultados disponibilizados por escola e por ente federativo.

- A Avaliação Nacional da Alfabetização - ANA : avaliação censitária envolvendo os alunos do $3^{\circ}$ ano do Ensino Fundamental das escolas públicas, com o objetivo principal de avaliar os níveis de alfabetização e letramento em Língua Portuguesa, alfabetização Matemática e condições de oferta do Ciclo de Alfabetização das redes públicas. A ANA foi incorporada ao Saeb pela Portaria $n^{\circ} 482$, de 7 de junho de 2013

A Aneb e a Anresc/Prova Brasil são realizadas bianualmente, enquanto a ANA é de realização anual. 
Id on Line Revista Multidisciplinar e de Psicologia

Id on Line Multidisciplinary and Psycology Journal

Os exames cognitivos são elaborados a partir da matriz de referencia, que tem como parâmetro o que é comum a diferentes propostas curriculares a nível nacional, estadual e municipal, além da consulta a educadores nas áreas de português e matemática e do exame dos livros didáticos mais utilizados nos anos avaliados.

Mesmo assim, levando em consideração o que é fundamental na aprendizagem escolar dos alunos e, por tanto, o que todos educandos deveriam saber ao final de determinados anos (finais de ciclo), por ser amostral tem um baixo nível de interferência na vida das escolas e no currículo escolar.

Assim, torna-se adequada naquilo que se propõe em sua essência, que é diagnosticar e monitorar a evolução da qualidade da educação básica no território nacional, não permitindo medir a evolução do rendimento individual dos educando ou dos estabelecimentos de ensino. Sendo assim, os resultados são divulgados de forma agregada, não possibilitando a aplicação de políticas de responsabilização de educadores e gestores para melhoria da qualidade da educação nas unidades escolares.

\section{Análise dos resultados das avaliações em larga escala: Prova Brasil}

As avaliações tem o objetivo de sinalizar, para todos, a situação da qualidade da educação básica no território brasileiro; Sendo de interesse aprofundado dos governantes, dos gestores escolares e dos educadores, com o intuito de corrigir os possíveis erros através das devidas intervenções; Cada um dentro da sua competência.

Os resultados dessas avaliações são divulgados nas redes sociais, em jornais, revistas e nos meios de comunicações locais. Com isso, a sociedade passa a ter conhecimento sobre a situação da educação no país.

Conforme o jonal digital O Globo (2014), o resultado da Prova Brasil mostra queda de aprendizagem ao longo do ensino fundamental, devido o desempenho em Português e Matemática dos alunos piorarem progressivamente entre $5^{\circ}$ e $9^{\circ}$ anos do segmento.

Pense no efeito bola de neve: ela começa a rolar ainda pequena, cresce conforme desce a ladeira, ganha grandes proporções ao pé da colina e estoura assim que colide com alguma barreira. Substitua agora a bola pelo aluno com déficit de aprendizagem e 
troque a barreira pelo ensino médio. Assim, terá como resultado a ladeira se transformando no ensino fundamental, comprometendo o aprendizado nas últimas séries do segmento. Este é o resultado da análise feita pelo Núcleo de Jornalismo de Dados do GLOBO a partir dos microdados das três últimas edições da Prova Brasil, divulgados pelo Instituto Nacional de Pesquisas Educacionais Anísio Teixeira (Inep), que revelam: no percurso entre o $5^{\circ}$ e o $9^{\circ}$ anos, os alunos vão apresentando notas cada vez mais distantes das metas do Ministério da Educação (MEC) (Jornal o Globo, 2014).

Assim, a sociedade passa a conhecer os resultados e se preocupar com a educação, muitas vezes, tentam intervir pressionando os governantes, gestores escolares e professores, buscando melhorar o sistema de ensino para que todos tenham acesso a uma educação de melhor qualidade, com isso educadores e pesquisadores, buscam formas de ajudar, dando sugestões que viabilizariam o processo de melhoria.

Para o membro da Academia Brasileira de Educação Ruben Klein, o aumento da concentração de estudantes no nível mais baixo de aprendizado no $9^{\circ}$ ano em relação ao $5^{\circ}$ mostra que o problema mais grave da educação estaria nos anos finais do ensino fundamental (do $6^{\circ}$ ao $9^{\circ}$ ). Segundo ele, é nessa fase que o aluno começa a apresentar uma piora no desempenho médio, algo que se torna crônico quando ele avança para o ensino médio: - Muito se fala sobre o péssimo estado do ensino médio ou da alfabetização, mas, para mim, a raiz do problema está nos anos finais do fundamental. A Prova Brasil mostra que os alunos chegam relativamente bem ao sexto ano, mas a partir de então a escola não sabe aproveitá-los. O estudante não está evoluindo como deveria (Jornal O Globo, 2014).

Em fim, é necessário uma conscientização maior dos envolvidos no processo de aprendizagem e um envolvimento maior dos governantes com uma educação de melhor qualidade e gratuita, pois percebe-se nitidamente através dos resultados, que a qualidade vem decaindo com o passar dos anos e pode-se afirmar que os alunos estão aprendendo menos que o desejável.

\section{Considerações Finais}

Ao longo de vários anos os estudiosos e pesquisadores da educação vêm procurando, formas de solucionar os problemas que inviabilizam a construção de um sistema de educação 
Id on Line Revista Multidisciplinar e de Psicologia

Id on Line Multidisciplinary and Psycology Journal

eficaz, onde todos aprendam o que é necessário de acordo com a sua idade e ano que está cursando.

Assim, criou-se um sistema permanente de avaliação com o intuito de monitorar a qualidade da educação brasileira e estabelecer, dentro das possibilidades, novos parâmetros de gestão dos sistemas educacionais.

Dessa forma os resultados das avaliações, sejam externas ou internas, devem ser utilizados como parâmetro para criar ou redefinir as políticas educacionais, e como parâmetro para o desenvolvimento das ações pedagógicas a nível escolar, para que os gestores e educadores façam as devidas intervenções com base nos resultados.

Por tanto, a principal função da avaliação é subsidiar o professor, a equipe escolar e o próprio sistema no aperfeiçoamento do ensino. Fornecendo informações que possibilitam tomar decisões sobre quais recursos educacionais devem ser providenciados para tornar o ensino mais efetivo.

Em fim, a avaliação é uma ferramenta valiosa para gestão, quando utilizada com o propósito de entender e compreender o processo de ensino e aprendizagem que o educando está inserido, no qual o desempenho dos docentes e os recursos pedagógicos devem ser modificados para favorecer uma aprendizagem mais significativa e eficaz para todos os educandos.

\section{Referências}

BROOKE, Nigel. O futuro das políticas de responsabilidade no Brasil. Caderno de Pesquisa, São Paulo, v. 36, n 128, p. 377 - 401, 2006.

FREITAS, Dirce Nei Teixeira. A Avaliação da Educação Básica no Brasil: dimensão normativa, pedagógica e educativa. Campinas: Autores Associados, 2007.

INEP; Disponível: http://portal.inep.gov.br/internacional-novo-pisa-paisesparticipantes; Acesso: 14/07/2016 às 7h $30 \mathrm{~min}$.

INEP; Disponível: http://portal.inep.gov.br/web/saeb/aneb-e-anresc; Acesso em: 19/07/2016 às $21 \mathrm{~h} 15 \mathrm{~min}$.

JORNAL DIGITAL O GLOBO; Disponível: http://oglobo.globo.com/sociedade/educacao/resultado-da-prova-brasil-mostra-queda-deaprendizagem-ao-longo-do-ensino-fundamental-14888905; Acesso: 19/07/2016 às 21h 46min; 
por Leonardo Vieira / Fábio Vasconcellos (Núcleo de Jornalismo de Dados); Em: 21/12/2014 às $6 h$.

\section{Como citar este artigo (Formato ABNT):}

ALBUQUERQUE, M.M.S.S.A. Avaliação externa como parâmetro para a Educação. Id on Line Revista Multidisciplinar e de Psicologia, Janeiro de 2017, vol.10, n.33, Supl 2. p. 103-111. ISSN: 1981-1179.

Recebido: $19 / 12 / 2016$

Aceito: 22/12/2016 